\title{
MONITORING THE STATE OF AGROCENOSIS WITH THE USE OF REMOTE-SENSING GYRO SYSTEM
}

\section{Malgorzata BZOWSKA-BAKALARZ ${ }^{1}$, Andrzej BIEGANOWSKi², Pawel Krystian BERES $^{3}$, Karl-Heinz DAMMER ${ }^{4}$, Katarzyna OSTROGA ${ }^{5}$, Lukasz SIEKANIEC ${ }^{3}$, Anna WIECZOREK ${ }^{2}$}

\author{
${ }^{1}$ University of Life Sciences, POLAND \\ ${ }^{2}$ Institute of Agrophysics, Polish Academy of Sciences, POLAND \\ ${ }^{3}$ Institute of Plant Protection National Research Institute, POLAND \\ ${ }^{4}$ Leibniz Institute for Agricultural Engineering and Bioeconomy, GERMANY \\ ${ }^{5}$ Polish Energy Group S.A, POLAND \\ E-mail of corresponding author: malgorzata.bzowska@up.lublin.pl
}

Keywords: precision agriculture, gyrocopter remote sensing system, hyperspectral imaging, GHG mapping, decision support system

\begin{abstract}
The aim of the project is the development of a decision support system (DSS) for precision farming. It is based on remote sensing to assess condition of agrocenoses and define requirements for cultivation operations (irrigation, fertilizing, and pest control). The remote sensing method is to be used for monitoring winter wheat and maize as well as for assessing degradation level of meadows on the basis of intensity of carbon dioxide and methane exchange between the ground surface and the atmosphere. The paper discusses application of an ultralight autogiro as an efficient carrier of remote sensing equipment. The project is cofinanced by the National Centre for Research and Development, BIOSTRATEG grant no. 298782.
\end{abstract}

\section{INTRODUCTION}

Precision agriculture is a management strategy based on the assessment of local, specific soil and plant properties, which specifies appropriate timing and doses of application of irrigation, plant protection products, fertilizers, etc. or machine operating parameters in order to optimise the use of soil resources and production potential of plants with minimal hazards to the environment. Production practices are adapted to the needs and condition of plants in individual field fragments (Gozdowski at el. 2007; Dammer at el. 2015). The advantages of precision agriculture are currently widely accepted, but it is profitable mainly in large-scale farms. It is possible to increase profitability through development of novel and more cost-efficient methods for acquisition of the most complete information possible about the condition of the entire field (soil and plants) (Dąbrowska-Zielińska at el. 1998; Strachan at el. 2002). Precision farming is vital for the required sustainable intensification (Chen at el. 2011, Day at el. 2008). State-of-the-art precision farming has demonstrated yield increases of 3.7\% with 7\% less N-fertiliser (Hobbs at el. 2008).

So far, acquisition of data required for implementation of precision agriculture is mainly achieved by ground-based examinations of soil and plants (Bereś 2013, Bieganowski at el. 2013; Lamorski at el. 2014; Rook at el. 2014). However, this approach involves expensive chemical and biological analysis and is work- and time-consuming. A solution may be aerial data acquisition. However, the use of aircraft for these purposes has substantial drawbacks: operating costs (the need of flights to and from the airport and the high consumption of the expensive aviation fuel); high speed of the flight, resulting in a lower resolution of recorded images. When using unmanned aerial vehicles, there are other important limitations: the prohibition of the use of drones heavier than $25 \mathrm{~kg}$ imposed by law (Regulation of MTBiGM from March 26, 2013; Communication from the Commission to the European Parliament and the Council. April 8. 2014) which 
substantially reduces the capacity of drones, e.g. mounting of the hyperspectral highresolution system designed in this project, and impairs stability (particularly at stronger gusts of wind); the prohibition of flights above the altitude of $300 \mathrm{~m}$, which makes it impossible to increase the imaging band at the constant focal length of the scanner, thereby causing its low efficiency; the prohibition of flights out of pilot's sight, which impedes and prolongs the measurement in the case of high crops (maize) and large fields. A solution, which seems to be the most optimal, is the use of an ultralight aerial vehicle the gyrocopter. The gyrocopter is an ultralight aerial vehicle (from the family of rotorcrafts) equipped with a rotor and a push propeller (Fig. 1, 2) (Bzowska et al. 2015). Unique ultralight gyrocopter features became an origin of selection of this type of aircraft as a remote sensing system carrier. In order to assure sufficient lift and space for the equipment the three sided version of the gyrocopter was selected. A gyrocopter can operate from grasslands not specially prepared, located in the direct neighbourhood of an object to be scanned.

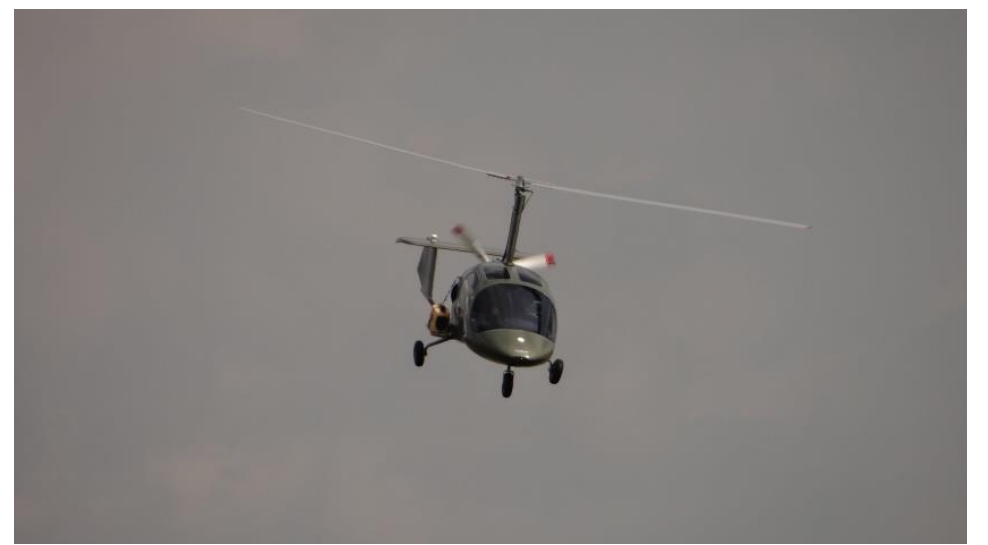

Fig. 1. Gyrocopter equipped with hyperspectral scanners (photo P. Turos)

In comparison to aircrafts, gyrocopters are cheap to operate; they can land on the field and burn car petrol (much cheaper and much more easily available) in amounts lower than are used by a plane. Simultaneously, their carrier capacity is sufficiently high to have no limitations on the requirements of camera sets and other sensors designed in this project.

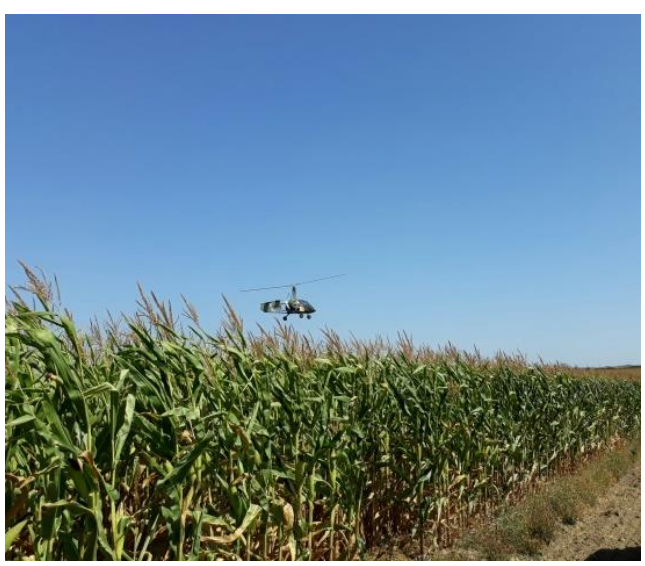

Fig.2 Gyrocopter flying over the maize (photo P. Grzybowski)

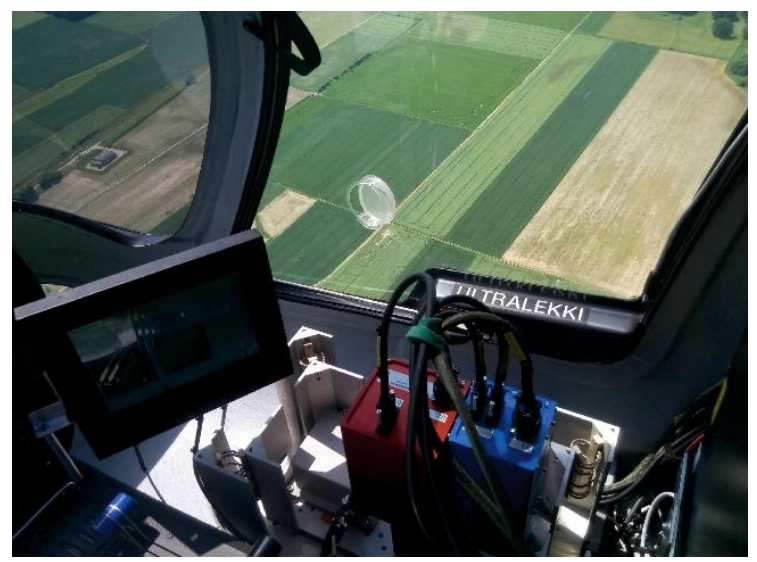

Fig 3. Hyperspectral cameras inside the gyrocopter (photo M. Bzowska) 


\section{OBJECTIVES AND METHODOLGY}

In contrast to the majority of hitherto applied solutions based on multispectral imaging (selected spectral channels of the spectrum are recorded and interpreted), this project is based on hyperspectral recording (i.e. in a wide spectral range from 400 to $2500 \mathrm{~nm}$ with a high spectral resolution of 2-10 nm). Spectral characteristics are recorded by two complementary-scope cameras (Fig 3). The use of a hyperspectral set allows application of a greater number of available interpretation techniques in the analyses of vegetation and soil and development of novel techniques through recording in a wide spectrum range.

The primary objective of the project GYROSCAN is to develop a Decision Support System (DSS) based on an analysis of hyperspectral images in order to identify the needs for agricultural treatments (irrigation, fertilisation, and chemical pest and disease control) in the context of the requirements and objectives of precision agriculture. Remote sensing methods will be employed for:

- evaluation of the meadow degradation degree (the level of biodiversity of vegetation occurring on the analysed meadow will be a measure of degradation)

- assessment of the intensity of carbon dioxide and methane exchange between the active surface and the atmosphere

The objectives of this project complement the tasks realised under the project Advanced Sustainable Agriculture Production (ASAP) .The concept of this project is presented in Fig. 4.

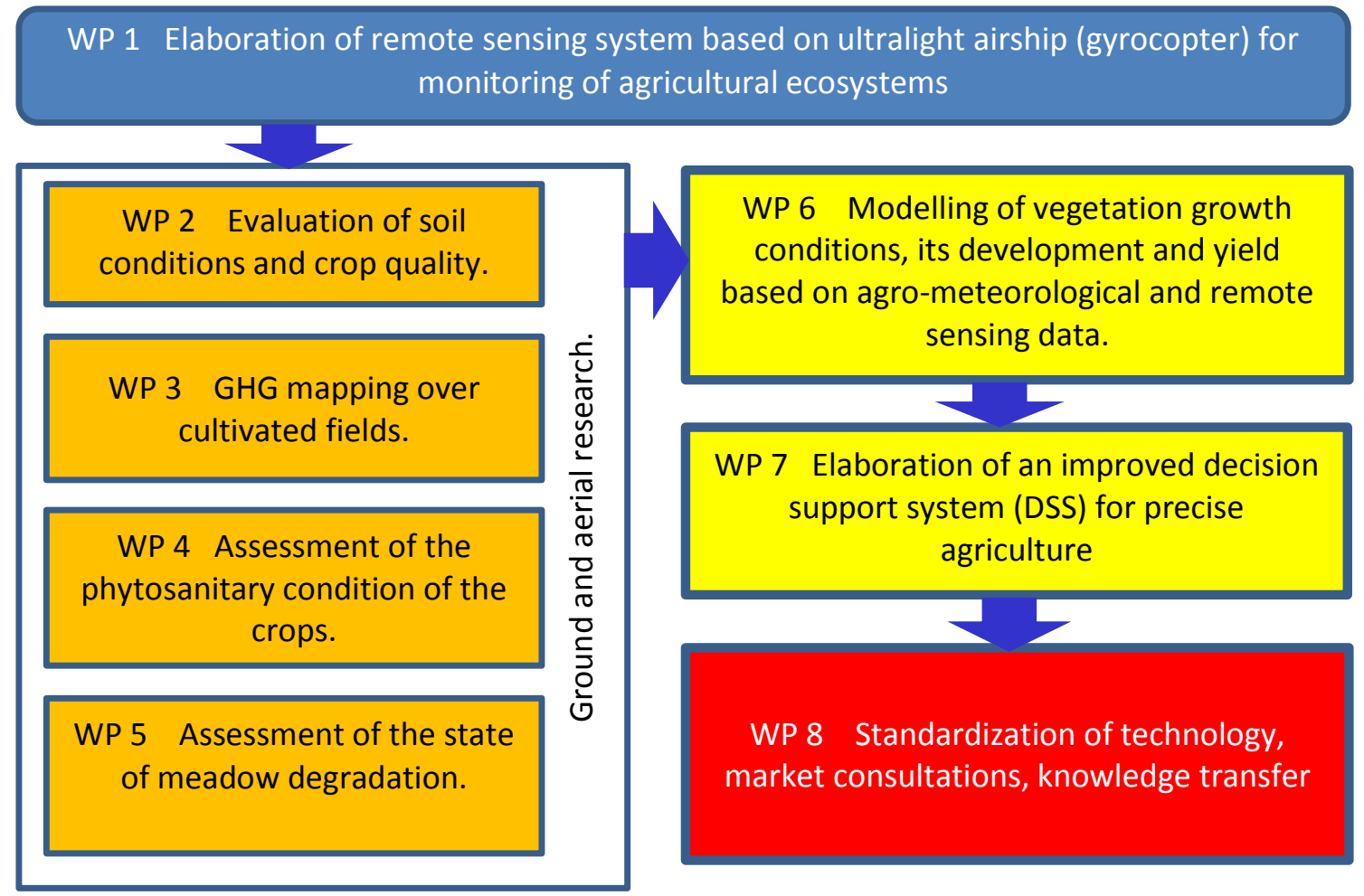

Fig. 4. Project scheme

A major advantage of the project is the consortium consisting of four scientific units such as the Institute of Agrophysics, PAS (leader), Institute of Geodesy and Cartography, the Institute of Plant Protection - National Research Institute, the University of Life Sciences 
in Lublin and three companies: Aviation Artur Trendak, Geosystems Polska Ltd. and Lesaffre Polska S.A. The consortium has been design in such a way that the qualifications and capabilities of all partners complement each other. Among the enterprises each one has great experience in a field of its business profile. Aviation Artur Trendak firm is an important (in Europe and globally) manufacturer of gyrocopters. It has extensive experience in flight services, also offered to farmers. Geosystems Polska is one of the leading companies in recording and interpretation of the hyperspectral spectrum. It has vast experience in operation of this type of systems and good knowledge of the market. Lesaffre Polska is experienced in ecological crop cultivation and is an excellent representative of potential recipients of the project results. Also, scientific units are leading in their field of expertise. Institute of Agrophysics, PAS, has substantial experience, proven by many reckoned publications, in physicochemical research of soil and plant properties, modelling of mass and energy transport processes in the soilplantatmosphere systems, and use of multi- and hyperspectral systems, including measurements and interpretation of results. The renowned Institute of Geodesy and Cartography is a strong scientific partner as well. This is confirmed by the experience derived from the involvement of the Institute in projects (also international). In the project, the experts from the Institute of Plant Protection - National Research Institute is assessed the degree of pest and disease infestations in the crop plants. Realisation of the full scope of the project would not be possible without a team specialised in meadow studies. This is provided by the team from the University of Life Sciences in Lublin, who specialise not only in identification of plants in meadow communities but has good knowledge of the study area.

Methodology is based on two main pillars: gyrocopter-based measuring system and field experiments (ground-based and aerial analyses). The measuring system consists of a set of cameras (hyperspectral imaging system) and the device for remote measurements of the concentration of greenhouse gases (GHG emission monitoring system) which are installed on board of the gyrocopter constructed and adapted for the purposes of the measurements. The whole measuring system is validated in a way that it is possible to record a spatial map of fields/meadows in the context of the hyperspectral properties of plants and soils, taking into account the parameters of the gyrocopter flight (Fig.5, 6).

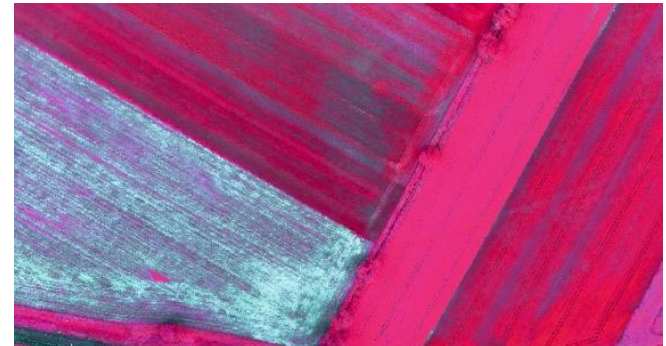

Fig. 5. Example of image recording in the infrared band

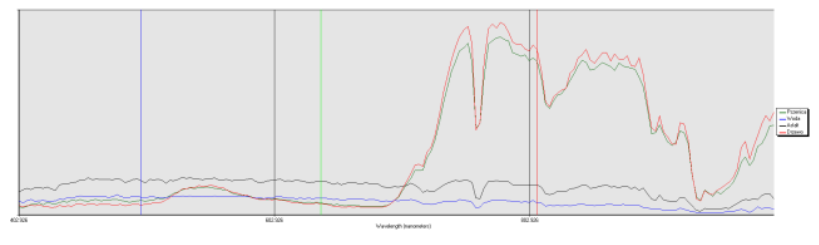

Fig. 6. Spectral characteristics representing different types of objects

After successful completing and the measuring system validation, the next stage of the project consists of a series of ground-based and aerial field analyses.

An important value of the project is the diversity of the scanned objects (agrocoenoses) investigated with the aim of calibration and validation of the model and DSS The crop plants (two most important Polish crops in large-scale farms, i.e. wheat and maize) are examined on the fields of a private large-scale farm in Rogów, Lublin Province, and fields 
located near Wołczyn, Opole Province. On the Rogów farm, reduced tillage is mainly applied (elimination of ploughing, as the treatment is energy-intensive and, according to many reports, does not bring positive results).

Lesaffre Company manages waste from yeast production (Lesaffre is a major world producer of yeast) by utilising it as organic fertilisers, in accordance with the aquatic legal documentation. Additionally, the company makes use of a developed fungicidal formulation (yeast-based fungicide). Hence, we decided to include investigations of crop plants cultivated on this farm as part of the proposed project.

The assessment of the degree of meadow degradation is carried out in a naturally and economically valuable area of the middle section of the Wieprz River (Lublin region), characterised by high habitat diversity.

The aim of ground-based research tasks is to acquire data about the soil conditions and plant status as well as for evaluation of the degree of meadow degradation. Many measurements and analyzes are made on soil, plants and atmospheric conditions. The seven measurement campaigns are conducted (once a month between April and November) during each of the vegetation seasons. Spectral characteristics (in the range of $400-2500 \mathrm{~nm}$ ) of the plant cover will be obtained for all the variants of the field experiments (32 variants in Rogów and 22 variants in Wołczyn) for various crop growth conditions.

The collected aerial data will be used to create high resolution maps which will support the DSS. Furthermore, on the base of the gathered hyperspectral data, the most suitable spectral bands/ranges and appropriate indices of plant water status, and phytosanitary status of plants are selected and evaluated. The actual crop water requirements, fertilization status, phytosanitary status is evaluated for all the growing stages on the base of the relations between the plant spectral characteristics and plant environment, including meteorological historical and prediction data, soil database information.

The data gathered from ground-based and aerial analyses will be used for development, calibration, and validation of the yield prognosis model and directly for development, calibration, and validation of the DSS. The added value of the solution will be a reduction of the amount of pollutants and GHGs emissions in the regional/national scale. Thus, this will contribute to an overall better life quality and human health.

\section{CONCLUSIONS AND PLANNED RESULTS}

The GyroScan project will deliver a comprehensive solution for an overall precision farming approach including a comprehensive DSS, reflecting both ecologic and economic costs. Its use will lead to reduction of the amount of fertilisers to the exact amount needed by the plants.

The final stage of the project will include development of the key project product, i.e. a calibrated and validated Decision Support System which will be composed of a gyrocopter-mounted hyperspectral registration module. The module will be fully coupled with the gyrocopter in a way allowing recording of the altitude as well as speed and direction of flight. This will contribute to precise mapping of the condition of the soil surface/plants and indication of areas where there is a need for undertaking specific agrotechnical treatments. Together with treatment recommendations (recommended doses of water and/or chemicals), the digital map will control the operation of the system. Downloaded to the module mounted on the area and/or on a tractor, the map will facilitate undertaking of recommended actions. Additionally, the yield prognosis model will 
contribute to specifying the terms of application of the required treatments for several days ahead, which will significantly help the farmer to optimize the time and use of the available infrastructure.

\section{ACKNOWLEDGEMENT}

The project is co-financed by the National Centre for Research and Development, BIOSTRATEG grant no. 298782

\section{REFERENCES}

Bereś P. K. (2013). Studium nad doskonaleniem integrowanej ochrony kukurydzy przed zachodnią kukurydzianą stonka korzeniową (Diabrotica Vigifera Vigifera Leconte) i omacnica prosowianką (ostrinia nubilalis HBN). Wydawnictwo. IOR-PIB. Poznań 2013

Lamorski K., Bieganowski A., Ryżak M., Sochan A., Sławiński C., Stelmach W. (2014). Assessment of the usefulness of practicle size distribution measured by laser diffraction for soil water retention modeling. View journal impact, 117, 803-813.

Bieganowski A.,Witkowska-Walczak B., Gliński J., Sokołowska Z., Sławiński C., Brzezińska M., Włodarczyk T. (2013). Database of Polish arable mineral soils: a review. International Agrophysics, 27(3), 335-350

Bzowska-Bakalarz M., Trendak A., Marszałek D. Pniak M., Bagar M., Czarnigowski J. (2015). Aerial method of plant protection with the use of autogyro in sustainable agriculture. Agricultural of Agriculture Science Procedia, 7, 54-58.

Chen X-P.,1, Cuia Z-L., Vitousek PM, Cassmanc K.G., Matsond P.A., Baia J-S., Menga Q-F., Houa P., Yuea S-C., Römhelde V., Zhang F.S. (2011). Integrated soil-crop system management for food security. Proceedings of the National Academy of Sciences of the United States of America, 108(16).

Dammer K-H., Hamdorf A., Ustyuzhanin A., Schirrmann M., Leithold P., Leithold H., Volk T., Tackenberg M. (2015). Target-orientated and precise, real-time fungicide application in cereals. Landtechnik, 70 (2), 3-43.

Day W, Audsley E, Frost A.R. (2008). An engineering approach to modelling, decision support and control for sustainable systems. Phil. Trans. R. Soc. B, 363, 527-541

Dąbrowska-Zielinska, K., Kogan, F., Ciolkosz, A., Gruszczynska, M., Raczka, U., Kowalik, W., Jankowski, R. (1998). New method of drought detection based on NOAA satellites and its impact on Polish agriculture. Proceedings of the ASPRS-RTI 1998 Annual Conference, Tampa, USA, 1501-1504

Gozdowski D., Samborski S., Sioma S. (2007). Rolnictwo Precyzyjne. Wydawnictwo SGGW.

Hobbs P.R, Sayre K, Gupta R. (2008) The role of conservation agriculture in sustainable agriculture. Phil. Trans. R. Soc. B., 363, 543- 555.

Strachan, I. B., E. Pattey, and J. B. Boisvert. (2002). Impace of nitrogen and environmental conditions on corn as detected by hyperspectral reflectance. Remote Sensing of Environment, 80(2), 213-224.

Rook, A.J., Dumont, B., Isselste in, J., Osoro, K., WallisDeVries, M.F., Parente, G. \& Mills, J. (2004). Matching type of livestock to desired biodiversity outcomes in pastures - a review. Biological conservation, 119, 137-150. 